Daimon. Revista Internacional de Filosofía, no 82,2021 pp. 125-140

ISSN: 1130-0507 (papel) y 1989-4651 (electrónico)

http://dx.doi.org/10.6018/daimon.352491

\title{
El concepto de castigo en H.L.A. Hart
}

\author{
The Concept of Punishment in H.L.A. Hart
}

JOSÉ MANUEL GRAGERA JUNCO*

\begin{abstract}
Resumen: Con objeto de establecer las bases de un castigo penal justo, H.L.A. Hart propone una visión alternativa a las versiones tradicionales. El planteamiento de Hart muestra que los enfoques principales no han superado problemas de incuestionable importancia: la justificación moral del castigo penal y su aplicación justa. En este sentido, el trabajo de Hart se sitúa entre el consecuencialismo y el retribucionismo. De esta manera, si un castigo está justificado debe tener buenas consecuencias para la sociedad castigando sólo a quien lo merece. Finalmente, la propuesta de Hart conectará con su concepción del Derecho dando a los individuos las capacidades de guiar su propia vida con previsión, confianza, seguridad y libertad.
\end{abstract}

Palabras clave: Hart-Castigo-Consecuencialismo-Retribucionismo-Justificación.

\begin{abstract}
In order to establish the basis of a fair criminal punishment, H.L.A. Hart proposes an alternative view to the traditional versions. Hart's approach shows that the main approaches have not overcome problems of unquestionable importance: the moral justification of criminal punishment and its fair application. In this sense, Hart's work is between consequentialism and retributivism. In this way if a punishment is to be justified must have good consequences on society punishing only those who deserve it. Finally, Hart's approach will connect with his own conception of law giving individuals the capacities to guide their own life with foresight, confidence, security and freedom.
\end{abstract}

Keywords: Hart-Punishment-ConsequentialismRetributivism-Justification.

\section{Introducción}

El principal objetivo de este trabajo es analizar y discutir el concepto de castigo penal en el filósofo del derecho H.L.A Hart. Para llevarlo a cabo centraré el foco en su obra Punishment and Responsibility. La versión del concepto del castigo que vamos a exponer se encuentra a medio camino entre los dos tradicionales enfoques, el utilitarista y el retribucionista. La postura de Hart, y seguramente uno de sus logros, es combinar estos dos enfoques en uno que permita promover sus virtudes minimizando los problemas en los que pueden incurrir.

Recibido: 04/12/2018. Aceptado: 25/06/2019.

* Doctorando en Estudios Avanzados en Humanidades en la especialidad de Filosofía de la Universidad de Málaga. Correo electrónico: chemagj@hotmail.es. Las líneas principales de investigación versan sobre cuestiones relativas a la filosofía del derecho, moral y política. Actualmente investigo sobre el papel de las excusas en la filosofía del derecho penal y la racionalidad práctica. Última publicación: "Justificación de las obligaciones en la justicia intergeneracional” en Oxímora. Revista Internacional de Ética y Política, n 12, 2018, pp. 141-159. 
En un primer momento, analizaré y cuestionaré qué queremos decir cuando hablamos de castigo, qué implicaciones tiene y cuáles son sus límites y su alcance. Así, previa definición del concepto, trataré los dos planteamientos principales a la hora de hablar de castigo legal. Mostrando sus peculiaridades, sus puntos positivos y negativos, procuraré asentar las bases de lo que será el posterior análisis y discusión del enfoque hartiano que nos ocupará el resto del trabajo.

Respecto al enfoque desarrollado por Hart a partir del segundo epígrafe, cabrá analizar dos cuestiones que son de suma relevancia para su correcta comprensión. Los primeros pasos los daré en torno a la separación de lo que justifica la práctica punitiva y la realización efectiva de dicha práctica. De tal manera, mediante un análisis debidamente consecuencialista y retribucionista, daré cuenta de un concepto de castigo en el que hay que separar diferentes niveles. Y la segunda cuestión que resulta capital son las ideas de la excusa y la mitigación (o atenuación), a través de las cuales el filósofo del derecho propone el castigo dentro de un sistema de elección que no se base en el miedo a ser castigado, sino que encuentre su basamento en la capacidad de procurar una maximización de la libertad de los individuos para guiar su vida con previsión, confianza y seguridad.

Finalmente, previo a las conclusiones que realizaré, mostraré algunas de las debilidades de las que adolece el planteamiento hartiano. En este sentido, haré hincapié en considerar que, curiosamente, uno de los principales éxitos de su teoría goza de cierta inconsistencia. Contra esto, intentaré proponer un enfoque más adecuado que consiga, manteniendo las líneas generales de la versión de Hart, dotar al concepto de castigo de un armazón teórico de mayor fortaleza y envergadura.

\section{2. ¿Qué es el castigo?}

Lo que primeramente hay que abordar, para conseguir entender la concepción hartiana del castigo, es cómo suele definirse el concepto del castigo y cuáles son los principales enfoques en cuanto a cómo entenderlo.

El castigo, hay que tener en cuenta, es un concepto que adolece de vaguedad; en este sentido, no es posible dar una única definición que cubra todos los casos posibles. Es necesario establecer cuáles son los casos centrales que caen dentro del concepto y cuáles son los periféricos; es decir, habrá que diferenciar lo que forma el núcleo de su definición y los casos que entran en este núcleo y aquellos que, aun perteneciendo al mismo término, se muestran como ligeramente diferentes.

Aquellos casos que se consideran centrales dentro de la discusión del castigo son los pertenecientes al castigo penal y constan de cinco elementos, a saber:

(i) Deberá implicar sufrimiento o alguna consecuencia de carácter desagradable. ${ }^{1}$

(ii) Deberá ser impuesto en virtud de un delito contra alguna ley.

(iii) Será impuesto a alguien considerado como infractor por su delito cometido.

(iv) Tendrá que ser intencionalmente administrado por personas diferentes al infractor o infractores en cuestión.

1 Todas las traducciones de textos originales en inglés al español son mías. 
(v) Se impondrá y administrará por una autoridad competente; esto es, constituida por un sistema legal contra el cual el delito, producido por el infractor, ha sido cometido.

Así, si este es un típico caso estándar de castigo, los casos periféricos serán, entre otros, los siguientes:

(a) Sanciones descentralizadas, donde entran aquellas infracciones contra reglas legales cuyo castigo no es impuesto por lo que podríamos considerar funcionarios del Estado.

(b) Castigos establecidos e impuestos dentro de, por ejemplo, una familia, un equipo de fútbol o el colegio. Éstos vienen caracterizados por tratarse de rupturas de reglas no establecidas por la ley.

(c) Castigo dirigido hacia responsables de un grupo social donde ciertas acciones de algunos miembros están realizadas sin el consentimiento, el control o la autorización de dicho líder o, en definitiva, jefe o persona responsable.

(d) Sanciones a personas que no son directamente culpables de alguna infracción. Este tipo de castigo supone una ligera variación del tipo c) $)^{2}$.

Aunque se utilice la caracterización de periféricos o subestándar para estos últimos casos sujetos de ser castigados, no significa que sean de menor importancia; de hecho, gozan de un gran valor si atendemos a que, como sucede en la realidad, no sólo existen las sanciones derivadas de la ley o del Derecho penal. Ejemplos de esto son los que se producen en el seno familiar, donde un padre puede, perfectamente, castigar a su hijo por haber roto algún objeto o por cualquier otro motivo que considere de peso. De modo, la importancia de éstos es precisamente constatar que no todos los tipos de castigos están o pueden ser castigados por la ley.

En lo referente a las principales teorías del castigo se hace imprescindible hablar de la versión retribucionista y utilitarista. El retribucionismo sostiene que a la hora de juzgar un delito e imponer una pena hay que mirar siempre hacia atrás en el tiempo, cuando la infracción fue realizada ${ }^{3}$. Como apunta $\mathrm{Hart}^{4}$, esta versión viene formada por tres elementos: en primer lugar, una persona será castigada si, y sólo si, ha realizado una acción moralmente negativa; segundamente, el castigo debe ser equivalente o proporcional a la maldad del ilícito; y, en tercer lugar, que la justificación de castigar a una persona bajo dichas circunstancias es la de infligir sufrimiento por una acción dañina ya realizada, siendo esto algo justo o moralmente bueno. El modelo utilitarista, por el contrario, no se caracteriza por esta suerte de mirada retrospectiva, sino que tiende a mirar hacia el futuro (forward-looking), concretamente a las buenas consecuencias posibles que redundarán en la sociedad. En este sentido, el castigo está justificado si repercute en la sociedad con una disminución de actos delictivos o el mantenimiento del orden legal; en resumen, favoreciendo con una sociedad mejor.

2 Cf. Hart, H.L.A. (2008), Punishment and Responsibility: Essays in the Philosophy of Law, Oxford: Oxford University Press, pp. 4-5.

3 Por esta misma razón también se la ha denominado un enfoque backward-looking, en referencia al carácter retrospectivo de la teoría. En términos parecidos se expresa Rawls sosteniendo que en castigos vistos desde una versión retributiva el juez mira al pasado aplicando una pena por algo que se hizo. Para ver este argumento de Rawls, ver Rawls, J. (1995), “Two Concepts of Rules”, The Philosophical Review 64, pp. 3-32.

4 Hart, H.L.A., op. cit., p. 231. 
La distinción entre ambas posturas es clara: la primera ajusta el castigo en función de la maldad del ilícito realizado por su transgresor; y la segunda en virtud de unos efectos socialmente deseables. Sin embargo, el verdadero problema al que se enfrentan ambas concepciones viene derivado de las posibles acciones moralmente cuestionables que pueden cometer. En la concepción retributiva, el castigo puede malinterpretarse y aplicarse sin pensar en qué beneficiaría a la sociedad, por no hablar de que su principal baza (castigar al culpable por su ilícito) conlleva cierto componente moralmente censurable en la medida en que castigar implica infligir sufrimiento sobre alguien. En cambio, la visión utilitarista puede poner su foco (equivocadamente) en lo que se ha etiquetado como "justificar demasiado", es decir, pudiendo incurrir en el hecho de acabar castigando a quienes se considerase (sean o no culpables), si tal acción es pensada como beneficiosa para la sociedad. De tal manera, el utilitarismo podría justificar demasiadas acciones.

\section{Justificación y distribución del castigo}

La teoría hartiana, frente a las ya mencionadas utilitarista y retribucionista, se caracteriza por ser una "teoría mixta". Uno de los grandes éxitos de su visión es señalar que, cuando hablamos del castigo, hay que distinguir dos niveles que abordan este concepto desde perspectivas diferentes: la propia institución del castigo y la aplicación del mismo. En otras palabras, de un lado existe la cuestión de qué motivos encontramos para justificar el castigo y, de otra parte, de qué manera lo llevamos a cabo. En estos términos, dejamos de ver el castigo como un todo inseparable de cuya puesta en escena se siguen tanto su justificación como sus posteriores acciones punitivas.

La propuesta de Hart pretende huir de la simplicidad conceptual y de valores. Él se muestra claramente consciente de que si algo caracteriza a las situaciones de interdependencia social es la pluralidad de valores, deseos y fines. Por lo cual, la misión es establecer las bases de una institución social y legal que provea de una serie de derechos y deberes fundamentales para el correcto funcionamiento de la sociedad y, además, sea capaz de dar voz efectiva a los deseos de los individuos. Así, lo que considero que plantea Hart es dar poder $^{5}$ a los individuos, de tal manera que éstos puedan cambiar conforme a la legalidad y a sus deseos la posición normativa que puedan ocupar en un momento determinado. ${ }^{6} \mathrm{La}$ clave está, por tanto, en proporcionar oportunidades, alternativas y capacidades.

Volviendo a lo anterior, para analizar con propiedad el concepto de castigo se debe separar la cuestión sobre su justificación y, por otra parte, la que atañe a cómo se distribuye dicho castigo. En un primer momento, voy a ocuparme de qué motivos justifican la existencia y puesta en marcha de esta institución, prestándome después a la tarea de desarrollar los fundamentos de una correcta aplicación del castigo legal en los términos en los que Hart se

5 Según la explicación de los derechos mediante correlativos y opuestos de Wesley Newcomb Hohfeld, que alguien tenga un poder o potestad implica que otra está sujeto a su poder (liability). De tal explicación se deduce que quien tiene dicho poder, tiene también la capacidad de cambiar la posición normativa propia y ajena (de quien está sujeto a su poder). De hecho, en este aspecto se entiende perfectamente el elemento (v) de la definición del castigo penal, en virtud del cual sólo una autoridad competente puede castigar. Cf., Hohfeld, W.N. (1992), Conceptos jurídicos fundamentales, México: Fontamara.

6 Hart, H.L.A., op.cit., p.10 
expresa. Si bien al castigo entendido desde una estrategia meramente utilitarista se le suele criticar que pueda "justificar demasiado" y, a la postura retribucionista, que considere infligir sufrimiento a alguien (culpable de un crimen) como algo valorable, la virtud del filósofo oxoniense será la de conjugar ambas doctrinas evitando los defectos que les son inherentes.

En lo referente a la justificación del castigo, H.L.A. Hart se sitúa en una posición claramente consecuencialista. No puede concebir una justificación para algo que implica sufrimiento sobre alguien si no redunda en consecuencias favorables para el resto de la sociedad. Precisamente esto, si se atiende a lo dicho más arriba, es una clara estrategia para evitar chocar con la crítica moral que se le achaca al retribucionismo.

Separar la justificación y distribución del castigo (a quién y cómo castigar) tiene sentido si se ve a la luz de la necesidad de aclarar cuáles pueden ser los objetivos principales del castigo como incentivar o desincentivar ciertos tipos de conducta para el mejor funcionamiento de la sociedad, y los pasos que se siguen para su consecución. En estos términos, una confusión muy habitual respecto a qué justifica esta institución es declarar que resulta de una "denuncia enfática (realizada por la comunidad) de un crimen". ${ }^{7}$ La solución a este error implica hacer efectiva la división que venimos mencionando. El objetivo de una ley penal no puede ser cualquiera de las cosas que se usan para justificar el castigo (denuncia enfática de la sociedad) porque, cuando hablamos de castigo (legal), hasta que no hayamos establecido qué conductas deben ser legalmente denunciadas o desalentadas, no podremos saber quiénes pueden ser considerados criminales para exigirles compensación, reparación o aplicarles el castigo correspondiente. ${ }^{8}$

Así, lo que propone Hart, es que por un lado se examine la justificación del castigo (General Justifying Aim) y por otro la legislación penal en su aplicación (Distribution). Lo primero hace referencia a qué objetivos o razones lo justifican y, lo segundo, a quién y de qué manera puede ser castigado. La justificación tiene que ver con una cuestión sobre el valor moral de la ley, sobre si realizamos mayor bien que mal al castigar a las personas por sus ilícitos. Mientras, la distribución pone su foco en casos particulares, en si resulta justo castigar a una persona bajo unas circunstancias concretas: "La primera, cuestión general que concierne a cada ley, es una cuestión de legislatura; la segunda, surgiendo en casos particulares, es para el juez. Y la cuestión de la responsabilidad surge solamente en el estadio judicial."9 Evidentemente, aunque separados, ambos momentos se encuentran conectados. Por tanto, se dan dos momentos que abordan diferentes cuestiones en el castigo. Una, sobre el valor moral de la institución (Justification); y otra, sobre lo justo o injusto de castigar a alguien por su delito en virtud de ciertas condiciones físicas y mentales.

Ahora bien, la dificultad a la que se enfrenta es la de cómo aplicar justamente medidas punitivas con un enfoque consecuencialista, con la posibilidad de incurrir en el sacrificio

7 Ibidem, p.7.

8 Ibidem, p.8.

9 Hart, H.L.A., ibidem, p.39. Otra forma análoga de defender la existencia de dos niveles conectados es la de Rawls, op. cit. Éste viene a señalar que el trabajo del juez, en tanto que juez, no es el mismo que el del legislador, en tanto que legislador. El primero, a la hora de juzgar, parece mirar al pasado (backward looking), mientras que el segundo suele encontrar la justificación a su oficio en una mirada al futuro (forward looking). En estos términos, la postura rawlsiana no es muy distinta de la que propone Hart (nótese el acento marcadamente utilitarista con el que se expresa Rawls). 
de una persona en pos del bien social. En este sentido, el retribucionismo da la clave poniendo la mirada en castigar únicamente al criminal por su crimen ya realizado. Así, Hart se posiciona como consecuencialista en el objetivo justificador y retribucionista en la distribución punitiva (Retribution in Distribution). En otras palabras: podemos defender el castigo por sus buenas consecuencias cuya persecución pasa por restringir el castigo sólo a los delincuentes por sus delitos cometidos.

Qué razones se encuentran para defender una institución social de este calado parece tener, en Hart, una clara raigambre valorativa. Eso significa que hablamos de qué fines o valores son moralmente aceptables de perseguir, lo que le lleva a proponer una visión consecuencialista a la vista del mal que supone provocar sufrimiento en alguien. En cambio, la aplicación del castigo no se libra de este componente moralmente perverso; así, hacer una buena defensa de la distribución pondrá sobre la mesa la importancia moral de la restricción del castigo a quien lo merece.

El valor de imponer sanciones punitivas a un infractor que actuó contra las reglas legales puede dilucidarse de, al menos, tres momentos. En primer lugar, una atención lo suficientemente comprensiva al utilitarismo puede mostrar que realizar, por ejemplo, castigos aleatorios o preventivos no ayudaría a conseguir el objetivo deseado, sino todo lo contrario. ${ }^{10}$ En un segundo momento, la combinación de retribucionismo en lo distributivo garantiza castigar a un criminal incluso en casos donde la ruptura de la ley pudiera pensarse como moral. ${ }^{11}$ Por último, la importancia moral de circunscribir el castigo a quien lo merece se importa del principio de distribución. Según este principio, aplicar sanciones por actos ilícitos no sólo implica preguntarse "¿quién debe ser castigado?”, sino también “¿cuánto, en qué medida y con qué severidad?".

En la forma en que lo entiende Hart, hablar de retribución en la cuestión distributiva del castigo asegura una medida de justicia frente a una retribución en tanto que justificación. Si a un sistema anclado en el mero retribucionismo le formulásemos las dos cuestiones anteriores, éste no llegaría más que a contestar a la primera (¿quién debe ser castigado?) con la respuesta "a un infractor por sus ilícitos". En cambio, este retribucionismo distributivo no sólo limita el castigo a un culpable, sino que también habla de cuál y cómo debe ser el castigo adecuado.

Entonces, recopilando, frente a sistemas exclusivamente utilitaristas y retribucionistas, la propuesta del filósofo inglés permite ciertas ventajas. Por un lado, evita los errores que pueden cometer las dos teorías tradicionales separando lo que justifica al castigo de su posterior aplicación; por otro, restringe la acción punitiva únicamente a quien lo merece; y finalmente, promueve un principio de justicia poniendo el foco en cuánto y en qué proporción deben ser sancionados los culpables. Este es el punto que voy a tratar ahora.

10 Rawls, J., op. cit., pp. 4-13.

11 Tal y como entiende Hart el retribucionismo, castigar a un delincuente por su delito se deriva de la inmoralidad de la ruptura de la ley. De modo que, si proponemos la retribución como justificación del castigo tendremos problemas en sistemas en lo que (como en la Alemania nazi) existen leyes moralmente detestables. Entraríamos en la situación en la que actuar moralmente bien conllevaría castigo. Ver Hart, H.L.A., op. cit., p.12. 


\subsection{Castigo dentro de un sistema de elección}

La segunda parte de este epígrafe tratará, como anunciaba al comienzo, de examinar sobre qué pilares podría asentarse el edificio de una ley penal. Hacer referencia al tema de la distribución del castigo no sólo es tratar cuestiones referentes a la cantidad o la severidad del éste, sino que también nos lleva a hablar de su restricción y de justicia. Sin entrar en excesivos detalles pues esto llevaría demasiado lejos del propósito de este trabajo , la idea de la Retribution in Distribution hartiana tiene que ver con la voluntariedad a la hora de actuar y con el ser responsable o no de un crimen cometido ${ }^{12}$. Las ideas principales dentro de este ámbito del castigo son las de mitigación y excusas o condiciones excusadoras (excusing conditions), las cuales pueden representarse como circunstancias de coacción, enfermedad, provocación o aquellas formas que hagan de una acción no intencional o donde el individuo no pueda expresar su voluntad o ésta no sea demostrable..$^{13}$

Expresado en estos términos, de la noción de mitigación se seguirían dos principios de justicia, a saber: a) los casos iguales en gravedad deben ser tratados igualmente y $b$ ) casos de diferente gravedad deberán ser juzgados de formas diferentes. Aunque dichos principios gozan de cierta vaguedad, la clave para acceder a ellos se encuentra en el momento en que dos crímenes difieren en cuanto a conocimiento de la situación, voluntariedad, coacción, etc. En otras palabras, el punto para las diferencias de trato respecto a los diferentes delitos se sitúa en las condiciones mentales y físicas del individuo; es decir, si su acción cae bajo ciertas condiciones que lo excusen ${ }^{14}$ (que eximan de toda responsabilidad) o justifiquen ${ }^{15}$ (que otorguen responsabilidad, pero no sujeción al castigo). Así, por tanto, un sistema se vuelve más justo al no castigar con la misma dureza un homicidio voluntario que uno realizado bajo condiciones físicas y/o psíquicas anormales. En última instancia, por tanto, estamos hablando de principios de justicia y proporcionalidad del castigo.

Cierto es que, la línea que separa las circunstancias justificadoras, atenuantes (mitigation) y que excusan un ilícito, es bastante difusa. Aún con todo, que un acto que supone una ruptura de la normatividad legal esté justificado o excusado, en términos generales suele eximir de responsabilidad criminal al agente actuante. En cambio, un atenuante no elimina la responsabilidad del ilícito, sino que juega a favor de quien actuó disminuyendo la pena. En la práctica, no siempre es del todo sencillo discernir si un individuo pudo haber ayudado

12 Sirva como apunte que Hart no considera la culpabilidad moral condición necesaria para que exista responsabilidad criminal (liability to punishment). En este aspecto, se desmarca de la versión retributiva. Ver ibidem, p.14.

13 Ibidem, p.15.

14 Un planteamiento distinto respecto a la concepción de las excusas de Hart es el expuesto por John Gardner, según el cuál las excusas juegan el papel de reafirmar la responsabilidad del individuo y, de igual manera que propone Hart, eximen de castigo. Véase, Para un análisis diferente de las implicaciones de las excusas, véase Gardner, J. (1998): “The Gist of Excuses” en Buffalo Criminal Law Review, vol. 1, no 2, pp. 575-598; Gardner, J. y Macklem, T. (2004): "Reasons" en J. Coleman y S. Shapiro (eds.), The Oxford Handbook of Jurisprudence and Philosophy of Law, Oxford, Oxford University Press.

15 Un trabajo donde se analizan los conceptos de responsabilidad y justificación en Hart y, además, Joel Feinberg es: Gardner, J. (2008a) "Hart and Feinberg on Responsibility" en Kramer et al (eds.), The Legacy of H.L.A. Hart: Legal, Political and Moral Philosophy, Oxford: Oxford University Press. 
a que el delito no se produjera ${ }^{16}$. Por tanto, y aunque Hart no lo declara explícitamente, me inclino a pensar que la diferencia se encuentra, sobre todo, en una graduación en la intención del individuo. Donde la justificación de un acto se sigue de su intencionalidad, la excusa mostraría una falta de intencionalidad y racionalidad ${ }^{17}$. La atenuación, probablemente, pueda situarse en medio de estas dos condiciones.

Como se puede observar, el autor de Punishment and Responsibility otorga un especial lugar a las excusas en su sistema del castigo, las cuales suponen una medida de justicia. La contraparte de este sistema sería lo que él denomina como strict liability (responsabilidad objetiva); esto es, el hecho de castigar todos los crímenes sin atender a circunstancias o condiciones que puedan justificar o excusar el acto cometido. ${ }^{18}$ En este sentido, lo que se surgiría sería un sistema penal que, no sólo estaría mucho menos capacitado para hablar de proporción, sino que disminuiría considerablemente el poder de los individuos para percibir e identificar cuándo la ley se le aplicará efectivamente. El motivo es, básicamente, que un Derecho penal fundamentado únicamente en la responsabilidad objetiva no puede establecer una adecuada graduación en las penas puesto que no atiende a condiciones físicas o mentales de los individuos que excusen o atenúen la carga punitiva de un delito (caso del homicidio voluntario e involuntario). Por este último motivo también se explica la pérdida de percepción de los individuos sobre cuándo la ley se les aplicará, pues éstos no tienen información sobre bajo qué circunstancias están eximidos de responsabilidad criminal.

Como mencioné en los primeros compases del segundo apartado, la pretensión del autor - tal y como yo la percibo-, además de proponer un fundamento del Derecho penal completamente consistente y justo, es dotar a los individuos mediante dicho sistema de las capacidades oportunas para realizar su vida pudiendo elegir, en cada momento, qué hacer y qué ser. Es la idea de crear un sistema penal que dote a los individuos de las capacidades de previsión y confianza para ejercer su vida en libertad ${ }^{19}$. Visto de otra forma, es crear una guía de actuación que no solamente prescriba los derechos y deberes fundamentales, sino que dé a cada uno de los individuos justas oportunidades de elegir entre lo requerido por la ley para la protección de la sociedad o quebrantarla y pagar la pena. Más allá de resultar un mero planteamiento del castigo legal, este momento es de especial importancia porque conecta directamente con la concepción del Derecho como guía ${ }^{20}$ que plasma en su The

16 La dificultad se entiende en el momento en que debemos deliberar si, por ejemplo, un individuo estuvo tan atemorizado por una amenaza o tan sumamente coaccionado que no fue capaz de evitar ninguno de los actos, o si por el contrario realmente pudo haberlo evitado en alguna medida. Es una cuestión puramente del grado en que una persona pierde o mantiene sus capacidades físicas y mentales.

17 Aunque la excusa se base en la posible falta de intencionalidad y racionalidad del individuo en un momento concreto, no es en absoluto irracional. De hecho, goza de un gran sentido en la tarea de realizar un juicio justo y proporcional en virtud de las circunstancias y condiciones del individuo.

18 Ibidem, p.20.

19 Aquí interpreto que el concepto de libertad que maneja H.L.A. Hart es el de "libertad positiva" de Isaiah Berlin, donde hablaríamos más bien de una libertad centrada en el autodesarrollo, el autodominio o autocontrol, y no tanto de la simple idea de no estar constreñido por nada externo (libertad negativa). Ver Berlin, I. (1958), "Two Concepts of Liberty” en: Isaiah Berlin, (1969), Four Essays on Liberty, Oxford: Oxford University Press.

20 La concepción de Derecho como una guía que limita pero que a la vez da libertad a los individuos para actuar y desarrollar sus vidas creo que tiene buena influencia en esta obra. Además, tales consideraciones me parece que conectan bien con la de idea de libertad positiva de Berlin. Para una más detalla lectura del Derecho entendido como guía, cf., Hart, H.LA. (1997), The Concept of Law, Oxford: Clarendon Press. 
Concept of the Law. De tal modo, Herbert Hart no sólo expresa cómo entiende él el castigo penal, sino que lo hace completamente consistente con su percepción del Derecho.

Es en estos términos en los que se comprende la inclusión de las condiciones que excusan dentro del armazón del Derecho penal que propugna H.L.A Hart. Tal y como muestra, la gran virtud de dichas condiciones es la de proteger a los individuos frente a los reclamos del resto de la sociedad. ${ }^{21}$ Así, frente a un sistema que trabaje mediante la penalización de todos los delitos sin atender a circunstancias del agente (strict liability), el castigo complementado por medio de excusas opera en tres sentidos. Primero, maximiza el poder de los individuos de tal manera que pueden calcular la probabilidad con la que la ley criminal les será aplicada mediante determinadas sanciones. Segundo, introduce la intencionalidad del individuo como un factor a tener en cuenta en el momento de discernir si las sanciones se le deben imponer o no. De tal manera que, de existir voluntariedad en el acto, el agente habría podido decidir el coste de obedecer la ley frente al de quebrantarla y pagar la pena oportuna. Tercero, el sufrimiento que implica el castigo (sólo al culpable por su ilícito cometido) puede ser representado como el precio de algún tipo de satisfacción por la ruptura de la ley.22 Aquí, satisfacción podría traducirse por un cierto sentimiento de seguridad, de confianza o bienestar por saber que hay "un delincuente menos en la calle".

En definitiva, el gran logro de introducir esta idea es llevarnos directamente a la voluntariedad del agente, al hecho de si el individuo pudo o no fue capaz de decidir libremente entre mantener la ley o romperla. El punto no está, por tanto, en la mera excusa de un acto ante la sociedad y ante la ley. La idea vehicular es que una ley penal que se conjugue con condiciones excusadoras lleva a preguntarnos si el individuo actuó de manera informada y considerando su propia elección. Reconocer las excusas provee a todos los individuos de la ventaja de un sistema de elección (choosing system), maximizando su libertad. Un sistema que distribuye el castigo en virtud de si el individuo tuvo la capacidad de elegir libremente y poner, así, en su balanza de razones si actuar conforme a la ley o hacerlo contra lo que ella dicta. ${ }^{23}$

Finalmente, para terminar de cerrar esta idea del Derecho penal como un sistema de elección, debo hacer una breve comparativa con el modelo de Jeremy Bentham, tal y como Hart lo entiende. El sistema benthamita, el cual también incluye dentro de sí las excusas, es caracterizado por Herbert Hart como un sistema de "economía de las amenazas", de tal manera que las personas actúan conforme a la ley por el miedo al castigo. En otras palabras, que el Derecho penal se concibe como una serie de amenazas para mantener el correcto funcionamiento de la sociedad. Aquí, la idea a tener en cuenta es que las excusas ayudan a la ley penal a ser más eficiente en su tarea de infligir castigo. En otras palabras, las condiciones mentales del individuo son condiciones bajo las que las amenazas de la ley operan con la máxima eficacia. El castigo se vuelve máximamente eficiente castigando a quien lo merece para asegurar el mantenimiento de la ley. ${ }^{24}$

La diferencia, entre la postura de ambos autores, reside en la conexión o independencia de las excusas respecto de la eficacia del castigo. Lo que Hart defiende es que las condicio-

21 Hart, H.L.A. (2008), op. cit., p.44.

22 Ibidem, p.47.

23 Ibidem, pp. 44-49.

24 Ibidem, p. 40. 
nes excusadoras son aceptadas de manera independiente de la eficiencia de un sistema de amenazas. De hecho, tales condiciones probablemente disminuyan esta eficacia mediante un aumento considerable de los requerimientos necesarios para ser visto por la ley como criminalmente responsable de un ilícito cometido ${ }^{25}$, dando así un importante lugar a los errores, la coacción y otros estados físicos y mentales anormales en las consideraciones de los tribunales de justicia.

El sentido en que interpreto el rechazo hacia un sistema penal que trabaje bajo las amenazas de la ley (law's threat) es el de que los individuos no siempre se encuentran en la tesitura de deliberar acerca de seguir la ley o actuar en contra de ella. En multitud de ocasiones en la vida cotidiana, las personas simplemente cumplen la ley por ser las normas legalmente establecidas. Establecer normas ayuda y facilita los procesos deliberativos; es más, las normas pueden incluso suprimir las deliberaciones. La autoridad que les otorgamos a las reglas y las leyes hace que, en su mayoría, decidamos simplemente cumplirlas porque consideramos que es lo que debe hacerse. ${ }^{26}$ En estos términos, no se sigue de cumplir la ley que sea por efecto del miedo a las amenazas. Más bien, podríamos pensar que tal miedo lo tendrían aquellos quienes deliberan acerca de quebrantar la ley; es decir, quienes sopesan acerca de los costes y los beneficios de incumplir una norma. En cambio, para quienes deciden acatar las leyes el miedo se transforma en una garantía que ofrece la seguridad de que los comportamientos antisociales de una minoría serán controlados o sancionados legalmente. ${ }^{27}$

\section{Desajuste entre la justificación y la distribución}

En lo siguiente, centraré el foco en analizar y discutir una de las ideas claves de la concepción del castigo que hemos venido alumbrando. La idea que quiero someter a tal prueba es la que versa sobre la escisión de lo que he llamado la justificación y la distribución del castigo. Para tal tarea, la Introducción que realiza John $\operatorname{Gardner}^{28}$ a la obra principal que trato en este trabajo, resultará de lo más iluminadora.

El punto desde el que parte John Gardner es el concebir la justificación del castigo desde un sentido pluralista en su propia concepción, no tanto en la obra de Hart; es decir, que lo que justifique el castigo no sea un único elemento o valor. ${ }^{29}$ Desde el momento en que el castigo implica infligir sufrimiento sobre alguien, se necesita de un buen armazón teórico que lo justifique. Así, todo lo que ayude a contrarrestar la carga negativa de la imposición del castigo, debe ser bienvenida. En este sentido, el actual profesor de jurisprudencia de Oxford considera que la defensa del castigo hartiana debe incluir un ingrediente retributivo no sólo en la distribución, como ya bien hace sino también en su justificación general.

25 Ibidem, pp. 48-49.

26 Para un específico desarrollo de la autoridad otorgada a las normas y cómo facilitan los procesos deliberativos cf., Raz, J. (1991), Razón práctica y normas, Madrid: Centro de Estudios Constitucionales.

27 Hart, op. cit., p.50.

28 Gardner, J. (2008b), "Introduction" en: H.L.A. Hart, (2008), Punishment and Responsibility: Essays in the Philosophy of Law, Oxford: Oxford University Press, pp. XIII-LIII.

29 Cf., Gardner, J. (2012), Ofensas y defensas: Ensayos selectos sobre filosofía del derecho penal, Madrid: Marcial Pons. 
Es cierto que una de las virtudes de Hart al concebir el castigo en Punishment and Responsibility es proponer una visión pluralista, y de ahí que a su teoría se la caracterice como "teoría mixta" ${ }^{30}$. Ahora bien, Hart atribuye como único contrapeso a la carga negativa del castigo la meta de conseguir unas buenas consecuencias o una prevención del castigo. De tal manera que, si nos preguntamos sobre qué justifica el castigo, qué razones y motivos encontramos para crear una institución y práctica así, nos encontramos con la respuesta de las buenas consecuencias.

Como anteriormente señalaba, propone dos momentos que hay que distinguir a la hora de hablar del castigo; por una parte, la justificación general (la institución, como tal); y por otra, la cuestión de la distribución (a quién y cómo castigamos). Así, si hablamos de la institución, señalamos las buenas consecuencias y, si hablamos de la distribución, señalamos el castigo al criminal por su crimen ya realizado. Por tanto, Hart admite sobradamente que el castigo va al infractor por su ilícito, más allá de que lo que justifique el castigo sean las buenas consecuencias para la sociedad. Pero es aquí donde creo que empieza a torcerse su defensa.

Los motivos por los cuales Hart defiende el castigo para el infractor por su delito cometido nos remiten directamente a la justificación general del castigo; es decir, a la institución del castigo cuyas razones para actuar están basadas en la prevención de actos delictivos (buenas consecuencias futuras, en general). Esta es realmente la única razón positiva para actuar castigando. Entonces, si a un juez le preguntásemos: ¿Por qué castiga usted a X? Él debería respondernos con un "por las buenas consecuencias que traerá a la sociedad" porque ésta es realmente la única justificación para castigar, aunque el modo de hacerlo sea al criminal por sus ilícitos.

En cambio, si miramos a la naturaleza del castigo penal, considero que éste respondería a las cuestiones: a) cómo se castiga o qué implica el castigo; b) por qué se castiga; c) a quién se castiga; y d) quién puede castigar ${ }^{31}$. Así, si queremos justificar la práctica punitiva (¿por qué se castiga a X?), la primera respuesta debería ser "porque se ha cometido una infracción y, por tanto, la persona que ha realizado dicha acción es culpable de ir contra las reglas legales". En otras palabras, porque X ha cometido una ilícito.

Volviendo a la defensa hartiana, vemos que respecto de su regla distributiva no se encuentra una justificación en este sentido. ${ }^{32}$ Él expresa cómo funciona la distribución (castigando al culpable por su delito) pero al cuestionar qué razones hay para hacer eso, únicamente puede remitirnos a sus buenas consecuencias, pero no a que se realiza por un crimen, real o supuestamente, cometido. Es decir, que los motivos de su regla distributiva descansan sobre la justificación de la institución del castigo. Dicho de otro modo, dentro de las razones existentes en la distribución del castigo para castigar al infractor por su

30 Sobre este aspecto, a Hart se le acusa desde algunas posturas de crear una teoría mixta del castigo; en cambio, Gardner, afirma que en absoluto ese es su problema; el problema es que es una teoría incompleta, que no es lo suficientemente mixta. Véase, Gardner, J. (2008b), op. cit., pp. XXVIII-XXIX.

31 Véanse los casos centrales en el epígrafe “1. ¿Qué es el castigo?”. Mi interpretación, por tanto, es que para justificar el castigo no debemos irnos al punto (i), que es la opción que Hart cree que justificaría el castigo con una visión retribucionista el cual considero más bien relativo al funcionamiento, es decir, a cómo o qué implica castigar. En su lugar, me parece una justificación más adecuada basarnos en el punto (ii) que es realmente lo que contestaría a un porqué.

32 Gardner, J. (2008b), op. cit., p. XXV. 
infracción, encontramos las futuras consecuencias esperables. Con esto no quiero decir que Hart no considere que el castigo deba aplicarse por un delito ya cometido, en absoluto; sino que al ponernos en el lugar de quien aplica una pena (el juez) y observamos qué razones encuentra éste para realizar tal acción, en última instancia, el modelo hartiano nos remitiría a la idea de las consecuencias futuras y no al ilícito cometido por su respectivo culpable. ${ }^{33}$

El punto que quiero mostrar puede comenzar a vislumbrarse en la concepción de Rawls de los dos tipos de reglas. ${ }^{34}$ Como él apunta, hay que diferenciar de manera clara lo que es una práctica en el sentido de estar regida por alguna regla y lo que es una acción que cae bajo esa regla o práctica. En este sentido, lo que Rawls propone es que a la hora de justificar una acción particular que se encuentra bajo el marco de una práctica, las razones debemos buscarlas en esa misma práctica, en esa regla que establece el método de actuación en casos concretos. En definitiva, la justificación debe remitir a la práctica; para lo que nos concierne, a la institución del castigo. Hasta este momento no hay nada nuevo. H.L.A. Hart también supedita las razones de infligir carga punitiva a la justificación general del castigo (General Justifying Aim). ${ }^{35}$ Pero es en este preciso instante donde tenemos el problema: cómo justificar el castigo por un delito, a un infractor, si dentro de las razones para esta institución no hallamos la consideración de aplicar la práctica punitiva a un delincuente por su delito.

Una solución a tal dificultad creo que podría venir de la mano de admitir una pluralidad de valores que justifiquen la práctica del castigo (como institución) y si consideramos el hecho de castigar a quien lo merece no como una de las razones que entran dentro del balance deliberativo para conseguir una sociedad mejor, sino como una razón para actuar por razones; es decir, una razón de segundo orden ${ }^{36}$ que dice qué motivos han de ser tenidos en cuenta para castigar y cuáles deben ser rechazados. La cuestión no es que la razón de castigar por un delito a un infractor sea la única que deba justificar la institución y la aplicación del castigo esto nos lleva a algo moralmente despreciable como buena cuenta da Hart, sino que ésta trabaje a modo de filtro, junto con otros motivos, para valorar por qué podríamos mantener una práctica de estas características. Como indica Gardner:

Hay muchas posibles razones para castigar a la gente, pero el hecho de que un ilícito fue (supuesta o realmente) cometido es la única razón para castigar gente; de lo cual es verdad que uno no es alguien que castiga ${ }^{37}$ a menos que actúe por esta razón. Las otras son opcionales pero esta razón (llamada razón R) es esencial. Que uno no sea un castigador, a menos que uno actúe por la razón R, no implica que uno no sea un agente castigador a menos que $\mathrm{R}$ sea la razón primordial para castigar. Esto sólo implica que uno no es un agente que castiga a menos que uno trate las

33 Tal problema es, curiosamente, en el que incurre el consecuencialismo indirecto, el cual, aunque se caracterice por fijarse en las reglas puede acabar tendiendo de nuevo hacia una valoración de las acciones caso por caso.

34 Cf., Rawls, J., op. cit.

35 De hecho, una de las grandes virtudes de su sistema es hacernos ver: primero, que existen dos momentos diferentes en el castigo (justificación y distribución) y segundo, que la distribución debe regirse por las razones del primer momento.

36 Para una detallada explicación acerca de las razones de segundo orden, cf., Raz, J., op. cit.

37 Por hacer más sencilla la lectura intercambiaré la expresión alguien que castiga con agente que castiga o castigador, aunque esta no sea la traducción literal. 
otras razones, por las cuales uno actúa, como razones para actuar por la razón $\mathrm{R}$ (por ejemplo, como razones-para-castigar ${ }^{38}$ en lugar de como razones para actuar inflingiendo daño). Esto es consistente con considerar la razón R como una razón de insignificante peso en sí misma, una razón que nunca sería suficiente por sí misma para defender cualquier acción punitiva..$^{39}$

Lo que viene a señalar es que, dentro de las razones de alguien que va a postularse como un agente que castiga, siempre debe aparecer la razón de castigar (a un criminal por su crimen). Después, a la hora de justificar por qué se castiga a una persona, podremos exponer muchos otros motivos que es algo bueno para la sociedad, que aumenta la seguridad del Estado o que incrementa la autoridad del mismo, pero dicha razón es necesaria y suficiente para castigar a alguien ${ }^{40}$. La confusión de Hart, probablemente, es considerar tal razón únicamente como condición necesaria ${ }^{41}$, según la cual que exista un delito cometido por un culpable es necesario para aplicar un castigo. En otras palabras, sólo se puede castigar a alguien que ha roto la ley, de otra manera no sería castigo.

El problema es que, si mantenemos este discurso, podríamos vernos sorprendidos por situaciones en las que ciertos delincuentes no sean castigados por diversos motivos. En pocas palabras, que en la práctica punitiva necesitemos un crimen y un criminal no implica que todos los crímenes deban ser castigados. La "obligación” sólo existe en el lado del castigo (que debe tener un ilícito y un transgresor de la norma), pero no que todos los delitos sean suficientes para ser castigados. Otra forma de analizarlo:

También es cierto, como señala Hart, que uno no está castigando a D a menos que uno actúe por la razón según la cual el acto de uno hará sufrir a D. Pero esto, diferente de la razón mencionada en el texto, no es una razón para castigar a D. Más bien es una razón para hacerle otras ciertas cosas a $\mathrm{D}$, tales como encerrarlo, quitarle su dinero o lanzar rumores sobre él, en virtud de castigarlo..$^{42}$

Entonces, ¿en virtud de qué razones podríamos defender la institución del castigo? La obtención de buenas consecuencias para la sociedad castigando a quien lo merece, por ejemplo. ¿Qué razones para castigar podríamos poner en la balanza? Gravedad del delito, cantidad del daño producido, etc.; en suma, aquellas que vayan acorde a las razones de segundo orden que filtran los motivos por los cuáles podemos castigar. ¿Y cuáles para no castigar? Pues aquellas que vayan contra lo que dicta la norma; es decir, castigar a alguien inocente o a alguien cuya responsabilidad en la infracción no pueda ser demostrada o que sea simplemente inexistente; y esto no solamente porque no deba castigarse a alguien inocente, sino que, en virtud de una visión pluralista, también acarrearía nefastas consecuencias.

38 El recurso de convertir la expresión "razones para castigar” en un solo término mediante guiones es mío.

39 Gardner, J. (2008b), op. cit., pp. XXX-XXXI.

40 John Gardner considera que la relación entre un castigo y un delincuente por su delito es una condición necesaria y suficiente. Es decir, que el castigo puede darse si y sólo si existe un malhechor por su ilícito. Esto resulta interesante, porque cerca el castigo a un criminal y obliga a que sea castigado por su ilícito.

41 Hart, H.L.A. (2008), op. cit., p. 39.

42 Gardner, J. (2008b), op. cit., p.XXX. 
Como creo que acertadamente señala John Gardner, considerar una regla así, que justifique el castigo a quien lo merece, no implica que ésta deba ser de gran peso. ${ }^{43}$ Pero una adecuada justificación de la práctica particular del castigo necesita de una adecuada justificación de su institución. En este sentido, si nos ponemos en el papel de un juez, éste, guiado por el Derecho penal, no condena a alguien pensando sólo en las buenas consecuencias futuras para la sociedad ${ }^{44}$, sino que claramente valora que hay un crimen que se ha cometido y que hay un culpable de dicha infracción y, por tanto, sujeto de ser castigado.

En definitiva, creo que el problema en Hart está en que, o bien como plantea Gardner en la Introducción olvida defender la conexión lógica entre la cuestión de la justificación y la de la distribución ${ }^{45}$, o escinde completamente ambas características del castigo de manera que es fácil ver la coherencia de sus planteamientos en ambos niveles, pero de manera aislada y sin considerarlas parte de un mismo todo.

\section{Conclusiones}

Todo lo dicho hasta este momento, no es sino el intento de mostrar tanto las virtudes como los defectos del planteamiento de H.L.A. Hart. Seguramente, dos sean los grandes éxitos que se encuentran dentro de su concepción. Por un lado, dar cuenta de la necesidad de separar los niveles de la justificación y la distribución sea una idea capital para entender bien el castigo penal. Por otra parte, introducir las excusas y conectarlo directamente con la idea del Derecho entendido como guía. Realizar este movimiento de entender las excusas, no desde la eficacia del Derecho penal, como proponía Bentham, sino como una suerte de indicadores que permiten a los individuos disponer de las capacidades de previsión, confianza, seguridad y, en última instancia, libertad para guiar sus vidas, cambia radicalmente la manera de entender el Derecho penal: de ser una institución meramente punitiva pasa a ser una institución que promueve la máxima libertad de los individuos. En pocas palabras, dejamos de vivir en función del miedo al castigo para empezar a vivir en un sistema de derechos que nos proporciona el poder y la capacidad de guiar nuestras vidas y desarrollarlas plenamente en libertad.

En cambio, considero que el problema que explicaba en el apartado anterior pone en serios apuros al filósofo. El desajuste entre la justificación y la distribución del castigo me parece la crítica más importante que podríamos hacerle. En este sentido, usando una analogía bélica, tal inconsistencia crea una brecha entre "las filas de sus tropas".

Bien es cierto que la inconsistencia surge de una mera objeción moral y no tanto de que Hart niegue la posibilidad de que, dar a los culpables lo que merecen, no tenga cabida en el objetivo justificador del castigo. Por ello, Hart apuesta por que lo que cuente principalmente en el castigo penal sea la inocencia del individuo y que, de tal manera, no prime la culpabi-

43 Ibidem, p. XXX.

44 Gardner, J. (2012), op. cit., p. 240.

45 Gardner lo expresa así: "Hart falla al advertir que hay dos características distintas del castigo que una adecuada defensa de la práctica debe defender. La primera es dictada por la moral y la segunda por la lógica. Habiendo defendido la primera con su argumento instrumental de la libertad, Hart se toma a sí mismo, erróneamente, como habiendo defendido (o más como obviando la necesidad de defender) la segunda." Gardner, J. (2008b), op. cit., p. XXVI. 
lidad. En cierto modo, es una forma de salvaguardar la moralidad de dicha institución al no dar prioridad al hecho de castigar e infligir el sufrimiento que lleva aparejado. Tal estrategia, junto con la aparición de las excusas en un sistema legal que guía a los individuos, resulta del todo coherente con que sea condición necesaria que, para que exista el castigo penal, deba haber un criminal que ha cometido un delito.

Lamentablemente, adolece de cierta debilidad. Como apunta Gardner ${ }^{46}$, del principio de castigar a quienes lo merecen se sigue que la culpabilidad es una buena razón para castigar y que la inocencia es una buena razón para no castigar. Sin embargo, la importancia de ambos hechos no es simétrica. Es decir, que defendiendo como condición únicamente necesaria el castigo para el culpable podemos encontrar más razones para no castigar que para hacerlo. Recordemos que esta condición necesaria deja abierta la posibilidad de no castigar ciertos crímenes por cualquier otro motivo, pues sólo exige la obligatoriedad de un criminal para hacer efectivo el castigo penal. Y si, además, tenemos en cuenta la inmoralidad de infligir sufrimiento, podemos encontrarnos con un sistema penal que encuentre muchas más razones que justifiquen no castigar un delito. En estos términos, resulta inevitable pensar que esa condición de necesidad no basta para darle fuerza al concepto de castigo.

Por tanto, el edificio del Derecho penal quedaría mucho más reforzado si se defendiera una pluralidad de valores que admita las buenas consecuencias a la sociedad, limitando el castigo a su infractor, y, a su vez, que castigar a los malhechores por sus ilícitos (mediante una justa valoración de posibles condiciones que justifiquen, excusen o atenúen) debe ser siempre condición necesaria y suficiente para una debida justicia penal. Así, la condición de necesidad limitaría el castigo a los culpables y la condición de suficiencia equilibraría la balanza anteriormente desestabilizada por la asimetría de tener más razones para no castigar que para hacerlo. El modo es claro, el equilibrio volvería al exigir que todo crimen deba ser penado. Algo que, junto con las excusas, asegura un castigo en proporción y justo. De no ser así, nos veríamos abocados a un sistema legal de raigambre puramente consecuencialista que, en última instancia, remitiría a un cálculo de buenas consecuencias caso por caso para dirimir no sólo la carga punitiva a un infractor, sino también si ciertos delitos se castigan o se dejan impunes.

\section{Referencias}

Berlin, Isaiah (1958), “Two Concepts of Liberty” en: Isaiah Berlin (1969), Four Essays on Liberty, Oxford: Oxford University Press.

Gardner, John. (1998), The Gist of Excuses” en Buffalo Criminal Law Review, vol. 1, n² pp. 575-598.

Gardner, J. y Macklem, T. (2004), "Reasons” en: J. Coleman y S. Shapiro (eds.), The Oxford Handbook of Jurisprudence and Philosophy of Law, Oxford: Oxford University Press.

Gardner, J. (2008a), "Hart and Feinberg on Responsibility" en Kramer et al (eds.), The Legacy of H.L.A. Hart: Legal, Political and Moral Philosophy, Oxford: Oxford University Press.

46 Gardner, J. (2012), op. cit., pp. 300-302. 
Gardner, J. (2008b), “Introduction” en: H.L.A. Hart (2008), Punishment and Responsibility: Essays in the Philosophy of Law, Oxford: Oxford University Press.

Gardner, J. (2012), Ofensas y defensas: Ensayos selectos sobre filosofía del derecho penal, Madrid: Marcial Pons.

Hart, H.L.A. (1997), The Concept of the Law, Oxford: Clarendon Press.

Hart, H.L.A. (2008), Punishment and Responsibility: Essays in the Philosophy of Law, Oxford: Oxford University Press.

Hohfeld, W.N. (1992), Conceptos jurídicos fundamentales, México: Fontamara.

Rawls, John (1955), "Two Concepts of Rules", The Philosophical Review 64: 3-32.

Raz, Joseph. (1991), Razón práctica y normas, Madrid: Centro de Estudios Constitucionales. 